\title{
Changes in respiratory function after one and three hours of exposure to formaldehyde in non- smoking subjects
}

\author{
Farhang Akbar-Khanzadeh, Jean S Mlynek
}

\begin{abstract}
Objective-To determine the changes in respiratory function within one hour and three hours of exposure to formaldehyde and investigate the relation between exposure to formaldehyde and acute changes in respiratory function.

Method-Respiratory function of 50 nonsmoking medical students exposed to formaldehyde in a gross anatomy laboratory were compared with respiratory function of 36 non-exposed, non-smoking physiotherapy students. Formaldehyde concentrations were measured in the breathing zone of each exposed subject and in the general work environment.

Results-Formaldehyde concentrations in the breathing zone of exposed subjects generally exceeded recommended standards. On average, the variables of respiratory function of both the exposed and the control subjects increased significantly within one hour and from one to three hours after exposure. The increase in respiratory function of the exposed subjects was significantly less than that of the control subjects. There was no meaningful correlation between concentration of formaldehyde in the breathing zone and changes in the respiratory function of exposed subjects.
\end{abstract}

Conclusion-As the increase in the respiratory function of the subjects can be attributable to normal diurnal variation, the significantly lower increase in respiratory function of the exposed group than in the control group is probably due to exposure to formaldehyde. The results of this study do not, however, support a dose-response relation.

(Occup Environ Med 1997;54:296-300)

Keywords: formaldehyde; respiratory function; short term changes

Medical College of

Ohio, Department of Occupational Health, Toledo, Ohio 43699-0008, USA F Akbar-Khanzadeh J S Mlynek

Correspondence to: Dr Farhang AkbarKhanzadeh, Medical College of Ohio, Department of Occupational Health, PO Box 10008, Toledo, Ohio 43699-0008, USA.

Accepted 20 November 1996 effects. ${ }^{1}$ Due to its high water solubility, more than $95 \%$ of inhaled formaldehyde is absorbed in the upper respiratory tract $^{23}$ and very little formaldehyde, if any, will reach the alveolar
Formaldehyde has widespread industrial plastics, rubber, particle board, plywood, ric coatings, and adhesives. It is also used as a preserving, disinfecting, and embalming agent

Formaldehyde has been reported to cause assortment of acute and chronic 1 membranes of the lungs. ${ }^{4}$ The toxic effects of formaldehyde on the upper respiratory tract are described as an irritant and as a sensitiser. ${ }^{1}$

The question of whether changes in respiratory function are associated with shift long exposure to low levels of formaldehyde remains controversial. Studies by Malaka and Kodama ${ }^{5}$ and Holness and Nethercott ${ }^{6}$ found no significant difference in the changes in pulmonary function variables across a shift. However, other studies showed that pulmonary function of workers exposed to formaldehyde decreased over the workshift. ${ }^{78}$

Acute pulmonary response to low level formaldehyde during periods shorter than a shift is also controversial. Spirometric measurements at intervals of $30,60,90,120,150$, and 180 minutes within a three hour exposure were performed by Sauder et $a l^{9}$ on nine healthy, non-smoking subjects exposed to $3 \mathrm{ppm}$ formaldehyde inside an environmental chamber. Small decreases in forced expiratory volume in one second $\left(\mathrm{FEV}_{1}\right)$ and forced expiratory flow during the middle half of the FVC $\left(\mathrm{FEF}_{25-75}\right)$ were found at 30 minutes, suggesting acute changes in lung function; however, these changes were not found at the other time intervals. This study concluded that maximal lung response to formaldehyde occurs early into the exposure and is short lived. Another study performed by Kulle et al ${ }^{10}$ on 19 healthy non-smokers showed no significant changes in pulmonary function test variables at any dose ranging from $0.5 \mathrm{ppm}$ to $3 \mathrm{ppm}$ for up to three hours. In one other study, Schachter et al ${ }^{11}$ performed a spirometry test under laboratory conditions on 15 non-smoking, healthy subjects exposed to formaldehyde. No acute nor subacute changes in lung function occurred with $5,15,25$, and 40 minute exposures to $2 \mathrm{ppm}$ formaldehyde during rest or exercise.

The published inconsistencies and the subsequent lack of agreement among researchers indicate the need for further studies to be performed in this area. Our previous study ${ }^{12}$ in a gross anatomy laboratory showed significantly more reduction in some of the variables of pulmonary function in the exposed subjects than in those of the controls. That study had a limited number of subjects and changes in respiratory function were studied within three hours only of the exposure to formaldehyde. Also, the concentrations of formaldehyde in the embalming solution used during that study have been increased to prevent growth of moulds on cadavers. Therefore, a follow up study was initiated to determine the changes in respiratory function within one hour and from 
one to three hours of exposure to formaldehyde and to investigate the relation between exposure to formaldehyde and acute changes in respiratory function.

\section{Material and methods SUBJECTS}

A total of 86 non-smoking subjects participated in this study. The group exposed to formaldehyde consisted of 50 first year medical students (25 men and 25 women) recruited from a medical school and the control group of 36 second year physiotherapy students (eight men and 28 women) attending the same institution. There were fewer male subjects in the control group than in the exposed group due to the limited number of matched control male subjects available in the institution during the time of the research work. The study was approved by the institutional review board for human subjects in the college.

Exposed subjects worked in the gross anatomy laboratory of a medical school. The laboratory room measured $37.5 \times 7.5 \times 3.5$ $\mathrm{m}$ and had nine doors, but no windows. The air was supplied through general ventilation, and the room contained 45 stainless steel dissecting work tables. While working in the laboratory, $98 \%$ of the exposed subjects wore protective gloves and laboratory coats, and $18 \%$ wore goggles. About 38 cadavers were dissected every day during this study. Simultaneously, control subjects attended their physiotherapy class lecture located in another building of the institution.

\section{RESPIRATORY FUNCTION TEST}

At least two control and two exposed subjects, matched as closely as possible for age, were evaluated on each test day. Test days were coordinated with the gross anatomy laboratory schedule which met formally three days a week from 900 am to noon. All scheduled participants were instructed to report to the testing laboratory 15 minutes before class time. Each morning of the study day, new subjects read, signed, and dated an informed consent form, and read and responded to the respiratory function questionnaire form.

Spirometric tests, which included forced vital capacity (FVC), $\mathrm{FEV}_{1}$, forced expiratory volume in three seconds $\left(\mathrm{FEV}_{3}\right)$, and $\mathrm{FEF}_{25-75}$ were performed while the subjects were seated and at rest. Three separate sets of spirometry tests were performed on each study and control participant on each test day. One investigator administered the respiratory function tests according to the guidelines prescribed by the American Thoracic Society. ${ }^{13}$ A portable spirometer, the Collins Survey Tach, was calibrated before testing on each study day. A 31 calibration syringe was used for this standardisation. Biological calibrations were also performed weekly by one of the researchers to ensure consistency of the results. Height, weight, age, sex, and race were entered into the computer program for respiratory function testing. Standardised instructions on how to perform the respiratory function test were spoken to each subject. Four efforts were attempted and the best test result recorded. This comprised the pre-exposure test. The exposed group subjects then went to the gross anatomy laboratory and began their dissections. They were instructed to return to the testing laboratory after one hour. Control subjects returned to their classroom lectures and were also instructed to return for the second set of respiratory function tests after one hour. The respiratory function tests, as described for the pre-exposure testing, were performed on all subjects for the one hour exposure test. Exposed subjects once again returned to the gross anatomy laboratory and controls returned to their class lecture. Both groups of subjects were instructed to return around 12 noon for the final set of respiratory function tests. These were designated as the three hour exposure tests. The barometric pressure and ambient temperature were recorded, and respiratory function variables were corrected accordingly. Basic (preshift) spirometric variables (FVC, $\mathrm{FEV}_{1}$, and $\mathrm{FEF}_{25-75}$ ) were expressed as a percentage of the reference values suggested by Knudson et al. ${ }^{14}$ Predicted vaues for $\mathrm{FEV}_{3}$ were those provided in the Collins Survey Tach computer software.

\section{EXPOSURE ASSESSMENT: AIR SAMPLING AND ANALYSIS}

Personal (breathing zone) and area formaldehyde samples were collected and analysed according to the National Institute for Occupational Safety and Health (NIOSH) method 3500. ${ }^{15}$ Each sample was collected with a constant flow pump (SKC Universal PCXR Samplers) and a series of two midget impingers containing $1 \%$ sodium bisulphite solution. Samples were analysed with analytical grade chemicals (Baxter Scientific Products) and a spectrophotometer (Spestronic 21D, Milton Roy Co.). The sample air flow rate was measured before and after each sampling by a precalibrated flow meter (SKC Accuflow film calibrator model 721). The barometric pressure and room temperature were measured during the collection of each set of air samples. Air volumes were adjusted to $25^{\circ} \mathrm{C}$ and $760 \mathrm{~mm} \mathrm{Hg}$.

\section{STATISTICAL ANALYSIS}

The data were entered into a computer for statistical analysis, which was performed with SPSS software version $6 \cdot 1$. Descriptive data included means (SDs). The $t$ test was applied where the differences of the means of two independent groups were compared. Paired $t$ tests were used for differences in the same day percentage changes of pulmonary function. Regression analysis was used to examine the relation between changes in pulmonary function and exposure to formaldehyde.

\section{Results}

SUBJECT PROFILE

Table 1 shows the personal data and the baseline respiratory function variables of all sub- 
Table 1 Personal data and basic (preshift; \% predicted) respiratory function of subjects

\begin{tabular}{|c|c|c|c|c|}
\hline & \multicolumn{2}{|c|}{ Exposed subjects } & \multicolumn{2}{|c|}{ Control subjects } \\
\hline & $\begin{array}{l}M e n \\
n=25\end{array}$ & $\begin{array}{l}\text { Women } \\
n=25\end{array}$ & $\begin{array}{l}M c n \\
n=8\end{array}$ & $\begin{array}{l}\text { Women } \\
n=28\end{array}$ \\
\hline Age (y) & $24 \cdot 2(2 \cdot 7)$ & $26 \cdot 4(5 \cdot 7)$ & $23 \cdot 1(2 \cdot 2)$ & $24 \cdot 1(6 \cdot 2)$ \\
\hline Height $(\mathrm{cm})$ & $175(7)$ & $163(5)$ & $172(4)$ & $165(6)$ \\
\hline Weight (kg) & $75 \cdot 4(13 \cdot 9)$ & $60.0(13.5)$ & $76 \cdot 5(8 \cdot 0)$ & $64 \cdot 6(8 \cdot 2)$ \\
\hline FVC & $110(16)$ & $117(18)$ & $109(13)$ & $120(13)$ \\
\hline $\mathrm{FEV}$ & $108(18)$ & $117(19)$ & $108(18)$ & $116(14)$ \\
\hline FEV: & $111(17)$ & $120(19)$ & $107(11)$ & $120(10)$ \\
\hline $\mathrm{FEF}=$ & $102(25)$ & $119(35)$ & $108(37)$ & $105(22)$ \\
\hline
\end{tabular}

Values are mean $(\mathrm{SD})$

Table 2 Mean percentage increase in respiratory function within the first hour from one to three hours, and within three hours

\begin{tabular}{|c|c|c|c|}
\hline & $\begin{array}{l}\text { Exposed group } \\
(n=50)\end{array}$ & $\begin{array}{l}\text { Control group } \\
(n=36)\end{array}$ & $t$ test \\
\hline \multicolumn{4}{|l|}{ Within $1 \mathrm{~h}$ : } \\
\hline FEV & $\begin{array}{l}1 \cdot 3(3 \cdot 8)+ \\
1 \cdot 2(4 \cdot 2) \dagger\end{array}$ & $2 \cdot 1(4 \cdot 4)^{\star \star}$ & t \\
\hline FEV & $1.8(3.4)^{\star \star \star}$ & $1.9(2.8)^{\star \star \star}$ & NS \\
\hline $\mathrm{FEF}_{5,5 ; \ldots}$ & $1.9(10 \cdot 2)$ & $3 \cdot 1(10 \cdot 3) \dagger$ & NS \\
\hline 1-3 h: & & & \\
\hline FVC & $0.9(3.0)^{\star}$ & $3.0(5.9)^{\star \star}$ & $\star \star$ \\
\hline $\mathrm{FEV}_{1}$ & $1 \cdot 2(3 \cdot 3)^{\star}$ & $4 \cdot 1(5 \cdot 0)^{\star \star \star}$ & $\star \star$ \\
\hline FEV; & $0.8(2 \cdot 8)^{\star}$ & $3.3(5.5)^{\star \star \star}$ & $\star$ \\
\hline $\mathrm{FEF}_{25}$ & $0.7(6 \cdot 6)$ & $6 \cdot 1(7 \cdot 0)^{\star \star \star}$ & $\star \star \star$ \\
\hline \multicolumn{4}{|l|}{ Within $3 \mathrm{~h}$ : } \\
\hline FVC & $2 \cdot 5(5 \cdot 4)^{\star \star}$ & $4 \cdot 6(6 \cdot 4)^{\star \star \star}$ & NS \\
\hline $\mathrm{FEV}_{1}$ & $2 \cdot 4(5 \cdot 1)^{\star \star}$ & $6 \cdot 2(7 \cdot 0)^{\star \star \star}$ & $\star \star \star$ \\
\hline FEV & $2 \cdot 7(4 \cdot 6)^{\star \star \star}$ & $5 \cdot 2(6 \cdot 5)^{\star \star \star}$ & $t$ \\
\hline $\mathrm{FEF}_{25}$ & $2 \cdot 2(9 \cdot 4)$ & $9 \cdot 3(11 \cdot 9)^{\star \star \star}$ & $\star \star \star$ \\
\hline
\end{tabular}

$+\mathrm{P}<0.1 ; \star \mathrm{P}<0.05 ;{ }^{\star}{ }^{\mathrm{P}} \mathrm{P}<0.01 ;{ }^{\star \star \star} \mathrm{P}<0.001$

All volumes are corrected to body temperature and pressure at standard conditions.

Table 3 Mean percentage increase in FEV, for study and control groups by sex

\begin{tabular}{|c|c|c|c|c|}
\hline \multirow[b]{2}{*}{ Period } & \multicolumn{2}{|l|}{ Study } & \multicolumn{2}{|l|}{ Control } \\
\hline & $\begin{array}{l}M e n \\
n=25\end{array}$ & $\begin{array}{l}\text { Women } \\
n=25\end{array}$ & $\begin{array}{l}M c n \\
n=8\end{array}$ & $\begin{array}{l}\text { Women } \\
n=28\end{array}$ \\
\hline Within $1 \mathrm{~h}$ & $1 \cdot 1(4 \cdot 7)$ & $1 \cdot 3(3 \cdot 8)$ & $1 \cdot 0(3.9)$ & $2 \cdot 4(4 \cdot 5)$ \\
\hline $1-3 h$ & $0.5(3.3)$ & $1.9(3.2)$ & $3 \cdot 2(4 \cdot 4)$ & $4 \cdot 3(5 \cdot 3)$ \\
\hline Within $3 \mathrm{~h}$ & $1.6(5.0)$ & $3 \cdot 3(5 \cdot 1)$ & $4 \cdot 3(6 \cdot 1)$ & $6 \cdot 8(7 \cdot 2)$ \\
\hline
\end{tabular}

Values are mean (SD). None were significantly different.

Table 4 Results of airborme formaldehyde sampling in a gross anatomy laboratory

\begin{tabular}{|c|c|c|c|c|}
\hline \multirow[b]{2}{*}{ Sample type } & \multirow{2}{*}{$\begin{array}{l}\text { Samples } \\
n\end{array}$} & \multirow{2}{*}{$\begin{array}{l}\text { Sampling } \\
\text { time (min) } \\
\text { mean }(S D)\end{array}$} & \multicolumn{2}{|c|}{ Concentration (ppm) } \\
\hline & & & mean $(S D)$ & range \\
\hline $\begin{array}{l}\text { Breathing zone } \\
\text { Area (middle of laboratory) }\end{array}$ & $\begin{array}{l}44 \\
76\end{array}$ & $\begin{array}{l}157(42) \\
160(29)\end{array}$ & $\begin{array}{l}1.88(0.96) \\
0.97(0.28)\end{array}$ & $\begin{array}{l}0 \cdot 30-4 \cdot 45 \\
0 \cdot 59-1 \cdot 72\end{array}$ \\
\hline
\end{tabular}

Table 5 Mean formaldehyde concentrations ( $\mathrm{ppm}$ ) related to body structure examined

\begin{tabular}{|c|c|c|c|c|}
\hline \multirow[b]{2}{*}{ Body structure examined } & \multicolumn{2}{|c|}{ Breathing zone sampling } & \multicolumn{2}{|c|}{ Area sampling (middle of the lab) } \\
\hline & $n$ & mean $(S D)$ & $n$ & mean $(S D)$ \\
\hline Back, shoulder & 4 & $2.52(1.07)$ & 6 & $1 \cdot 12(0 \cdot 41)$ \\
\hline Arm & 5 & $2.58(1.59)$ & 4 & $1.40(0 \cdot 14)$ \\
\hline Head, face, neck & 15 & $1.54(0.75)$ & 17 & $0.87(0.14)$ \\
\hline Thoracic wall & 0 & & 4 & $0.86(0.03)$ \\
\hline Lungs, heart & 4 & $2 \cdot 04(0.73)$ & 8 & $1.43(0 \cdot 26)$ \\
\hline Abdominal region, & & & & \\
\hline gastrointestinal tract & 8 & $1.81(0.97)$ & 18 & $0.80(0 \cdot 16)$ \\
\hline Urinogenital, anal, pelvic & 5 & $1.36(0.54)$ & 11 & $0.87(0.19)$ \\
\hline Gluteal region, thigh, foot & 3 & $2.41(0.49)$ & 8 & $0.95(0.09)$ \\
\hline
\end{tabular}

$\mathrm{N}=$ Number of samples collected.

jects. When segregated by sex, the two groups of exposed and control subjects were comparable for age, height, weight, and the baseline respiratory function.

RESPIRATORY ABNORMALITIES AND ACUTE IRRITATION REPORTED BY SUBJECTS

The study surveyed all subjects for their present respiratory health. In the exposed group, $4.0 \%$ of the subjects reported cough, phlegm, and shortness of breath. In the control group,
$8.3 \%$ of the subjects reported phlegm. Wheezing was not reported by any subject. Three $(6 \%)$ of the exposed subjects and one $(3 \%)$ of the control subjects reported a history of bronchitis. Four $(8 \%)$ of the exposed subjects and one $(3 \%)$ of the control subjects reported asthma.

The frequency of acute symptoms associated with exposure to formaldehyde was also investigated. Nose irritation was reported by $41(82 \%)$ of the subjects. Eye irritation was reported by $38(76 \%)$, throat irritation by 18 $(36 \%)$, airway irritation by seven $(14 \%)$, and skin irritation by six $(12 \%)$ of the subjects.

SHORT TERM CHANGES OF RESPIRATORY FUNCTION

Table 2 shows the mean (SD) of percentage changes $(100 \times$ (postshift value-preshift value)/preshift value) in respiratory function for exposed and control groups. The results of the changes in respiratory function showed that, on average, respiratory function increased in both groups for one hour and the increase continued from one to three hours. The women in both study and control groups showed a greater increase in respiratory function than the men, but the differences were not significant. Table 3 shows the mean percentage increase in $\mathrm{FEV}_{1}$ for study and control groups by sex. The other variables of respiratory function followed similar patterns. The respiratory function of the subjects with asthma also increased during exposure. In the exposed group, the mean percentage increase in respiratory function variables of the four subjects with asthma within three hours was higher than that of the 46 without (FVC $3.4 v$ $2 \cdot 4, \mathrm{FEV}_{1} 4.6 \vee 2.2, \mathrm{FEV}_{3} 3.9 \vee 2.6$, and $\mathrm{FEF}_{25} 4.3 v 2 \cdot 0$ ), but the differences were not significant.

EXPOSURE TO FORMALDEHYDE

Table 4 shows the airborne concentrations of formaldehyde in the gross anatomy laboratory, where the exposed group worked. Table 5 shows the differences in exposure to formaldehyde due to examining different sections of the human body. The sampling time covered the entire laboratory operation for one exposed subject. There was no meaningful correlation between the changes in respiratory function and formaldehyde concentration in the breathing zone of all the exposed subjects, those with asthma, or those with bronchitis.

\section{Discussion}

IRRITANT EFFECTS

This study confirms the irritant capability of formaldehyde and is consistent with other findings of similar studies. ${ }^{1211}$ The exposed group in this study reported symptoms of irritation of the nose $(82 \%)$ and eyes $(76 \%)$. Throat irritation was less often reported $(36 \%)$ by the exposed group. This is consistent with the research findings of Alexandersson et al who found that irritating symptoms of the nose and eyes appear first with signs of irritation of the throat after prolonged exposure to 
formaldehyde. Skin irritation was only reported by $12 \%$ of the exposed group in this study. In the laboratory in which this study was performed, protective gloves were readily available and used by the exposed group throughout the dissecting operations. Furthermore, several study participants indicated that double gloving was a common practice in the gross anatomy laboratory. The diligent use of this personal protective equipment is likely to be the reason for the low frequency of symptoms of skin irritation.

\section{SHORT TERM CHANGES IN RESPIRATORY FUNCTION}

The results of this study showed that respiratory function did not remain constant in the exposed group nor in the control group. It has been recognised that the variables in respiratory function are influenced by factors such as variabilities in the measurement, the observer, or the study subject. ${ }^{17}$ In this study, the time of day during which the tests were performed was standardised, the instruments were maintained and calibrated properly, and the tests were carried out by a single observer. This procedure was expected to have minimised the influence of undesirable factors.

Interestingly, changes in respiratory function are also related to circadian or diurnal variations. ${ }^{18} 19$ A study by Guberan et $a l^{20}$ showed a circadian variation of $\mathrm{FEV}_{1}$ in rotating shift workers and found that $\mathrm{FEV}_{1}$ increased by $0 \cdot 151$ during the morning shift (6 $00 \mathrm{am}$ to $200 \mathrm{pm}$ ) and decreased by 0.051 during the afternoon shift (200 pm to 1000 $\mathrm{pm})$. The present study evaluated the respiratory function of subjects between 730 am and $150 \mathrm{pm}$ and, therefore, the increase in the respiratory function at one and three hours through the experiment in both the exposed and the control groups may be explained by the circadian variation. Other studies ${ }^{21} 22$ have also confirmed the effects of circadian variation on respiratory function of workers in occupational environments.

The mean percentage increases in respiratory function for the first hour and from one to three hours after exposure were significantly greater in the control group than the exposed group. This implies that the exposure to formaldehyde may have inhibited the normal increase in respiratory function. These results are in agreement with those found in studies of funeral service workers ${ }^{6}$ and woodworkers ${ }^{8}$ who were exposed to formaldehyde. On the other hand, a study by Schachter et al ${ }^{11}$ showed that subjects' exposure to $2 \mathrm{ppm}$ formaldehyde for 40 minutes did not result in acute changes in respiratory function. It seems, however, that diurnal variation may explain some of the conflicting reports and disagreements on the direction of daily changes in respiratory function tests.

\section{EXPOSURE TO FORMALDEHYDE}

The measurement of breathing zone formaldehyde showed that all subjects were exposed to concentrations of formaldehyde greater than a $0.3 \mathrm{ppm}$ threshold limit value ceiling (TLV ceiling) recommended by the American Conference of Governmental Industrial Hygienists (ACGIH). A "ceiling" designation by the ACGIH indicates a limit that is not to be exceeded for any duration of time. ${ }^{1}$ The reason for this recommendation is to reduce the sensory irritation commonly encountered in workers who handle formaldehyde or products containing formaldehyde.

The United States Occupational Safety and Health Administration (OSHA) has gradually decreased the permissible exposure limit (PEL) for formaldehyde and the most recent amendment was to its current PEL of 0.75 ppm time weighted average (TWA) as a way to reduce the risk of chronic occupational disease, eye, nose, and throat irritation, and sensitisation. In this study, the calculated eight hour TWA concentrations showed that the exposure of $29.5 \%$ of subjects studied exceeded the OSHA-PEL of $0.75 \mathrm{ppm}$. In our previous exposure assessment ${ }^{12}$ in the same laboratory, the exposure of only $3 \%$ of subjects exceeded the limit of $0.75 \mathrm{ppm}$. Adding excess formaldehyde to embalming liquid to prevent the mould growth on cadavers has significantly increased the number of overexposed subjects. This study confirms the previous findings in this gross anatomy laboratory ${ }^{12}$ that the concentrations obtained were significantly higher when deep cavity structures were examined than when superficial structures were dissected. One objective of this study was to discover if there was a relation between acute respiratory changes and exposure to formaldehyde. The results of this research did not provide enough evidence of such a meaningful association. Nevertheless, a study by Malaka and Kodama ${ }^{5}$ of plywood workers exposed to formaldehyde showed a significant relation between chronic exposure to formaldehyde and reductions in respiratory function.

\section{Conclusions}

(1) All subjects were exposed to concentrations of formaldehyde in excess of the recommended ceiling limit by ACGIH and one third of the subjects were overexposed to formaldehyde according to OSHA PEL.

(2) The exposure to formaldehyde may have inhibited the normal diurnal variation in respiratory function.

(3) There was no meaningful association between acute respiratory changes and the levels of exposure to formaldehyde.

We acknowledge Dr Dennis E Morse, for his technical assistance and his cooperation with the logistics in this project, and Chong K Park for his help in data collection.

\footnotetext{
1 American Conference of Governmental Industrial Hygienists. Notice of intended change: formaldehyde. Hygienists. Notice of intended change:
Appl Occup Environ Hyg 1992;7:852-74.

2 Egle JL. Retention of inhaled formaldehyde, propionaldehyde, and acrolein in the dog. Arch Environ Health 1972; 25:119-24

3 Report of the Federal Panel on Formaldehyde. Environ Health Perspect 1982;43:139-68.

4 Gross P, Rinehart WE, deTreville TP. The pulmonary response to toxic gases. Am Ind Hyg Assoc $\mathcal{F}$ 1967;28: 315-21.

5 Malaka T, Kodama AM. Respiratory health of plywood workers occupationally exposed to formaldehyde. Arch
} Environ Health 1990;45:288-94. 
6 Holness DL, Nethercott JR. Health status of funeral service workers exposed to formaldehyde. Arch Environ Health 1989;44:222-7.

7 Main DM, Hermann E. The respiratory status of foundry workers exposed to formaldehyde [abstract]. $\mathrm{Am} \mathrm{Rev}$ Respir Dis 1984;129:157.

8 Alexandersson R, Kolmodin-Hedman B, Hedenstierna G. Exposure to formaldehyde: effects on pulmonary function. Arch Environ Health 1982;37:279-83.

9 Sauder LR, Chatham MD, Green DJ, Kulle TJ. Acute pulmonary response to formaldehyde exposure in healthy monary response to formaldehyde exposure
non-smokers. $₹$ Occup Med $1986 ; 28: 420-4$.

10 Kulle TJ, Sauder LR, Hebel JR, Green DJ. Formaldehyde dose-response in healthy non-smokers. Fournal of Air Pollution Control Association 1987;37:919-24.

11 Schachter EN, Tosun T, Witek Jr TJ, Beck GJ. A study of respiratory effects from exposure to $2 \mathrm{ppm}$ formaldehyde in healthy subjects. Arch Environ Health 1986;41:229-39.

12 Akbar-Khanzadeh F, Vaquerano M U, Akbar-Khanzadeh M, Bisesi MS. Formaldehyde exposure and acute pulmonary response, and exposure control options in a gross anatomy laboratory. Am F Ind Med 1994;26:61-75.

13 American Thoracic Society. Standardization of spirometry, 1987 update. Am Rev Respir Dis 1987;136:1285-98.

14 Knudson RJ, Lebowitz MD, Holberg CJ, Burrows B.
Changes in the normal maximal expiratory flow-volume curve with growth and aging. Am Rev Respir Dis 1983; 127:725-34

15 National Institute for Occupational Safety and Health Manual of analytical methods. Vol 1. Cincinnati, Ohio: NIOSH, 1989. (Publ No 84-100.)

16 Chia S, Ong CN, Foo SC, Lee HP. Medical students' exposure to formaldehyde in a gross anatomy dissection laboratory. $\mathcal{F}$ Am Coll Health 1992;41:115-9.

17 Hruby J, Butler J. Variability of routine pulmonary function tests. Thorax 1975;30:548-53.

18 Gamble JF, McMichael AJ, Williams T, Battigelli $M$ Respiratory function and symptoms: an environmentalepidemiological study of rubber workers exposed to a phenol-formaldehyde type resin. Am Ind Hyg Assoc $\mathcal{F}$ 1976;37:499-513.

19 Walford J, Lammers B, Schilling RSF. Diurnal variation in ventilatory capacity. Br f Ind Med 1966;23:142-8.

20 Guberan E, Williams MK, Walford J, Smith MM Circadian variation of FEV in shift workers. $B r f$ Ind $M e d$ 1969;26:121-5.

21 Dimich HD, Sterling TD. Ventilatory function changes over a workshift. Br $\mathcal{F}$ Ind Med 1981;38:152-5.

22 Love RG. Lung function studies before and after a work shift. Br $\mathcal{F}$ Ind Med 1983;40:153-9.

\section{Occupational and Environmental Medicine and the electronic age}

OEM has an Email address which is 100632.3615@compuserve.com.We welcome contact by Email, including letters to the editor. Some of our reviewers already send us their reports by Email, helping to speed up the peer review process.

We are moving towards electronic publishing and for some months now we have been asking authors to send us their revised papers on disk as well as a hard copy. I am delighted to report that nearly all our authors are managing to comply with this request. Oddly enough, the few authors who have not sent us a disk version of their revised papers have been almost exclusively from the United Kingdom. I would be interested in suggestions for why this might be. Perhaps United Kingdom based authors read our correspondence and instructions less assiduously? Watch for revised Instructions to Authors.

The Editor 